\title{
Gestão de riscos ocupacionais no manejo do lodo gerado em estações de tratamento de esgoto

\begin{abstract}
Management of occupational risks in the management of sewage sludge generated in wastewater treatment plants
\end{abstract}

Data de entrada: 26/08/2019

Data de aprovação: $17 / 12 / 2019$

Alysson Rogerio da Silva ${ }^{1 *} \mid$ Cali Laguna Achon ${ }^{1}$

DOI: https://doi.org/10.36659/dae.2021.031

ORCID ID

Silva AR (ID) https://orcid.org/0000-0002-5441-9590

Achon CL (D) https://orcid.org/0000-0001-5819-8089

\section{Resumo}

As ETEs desempenham papel crucial na manutenção da saúde da população. Porém, geram quantidade considerável de lodo de esgoto. Os custos relacionados ao manejo do lodo podem representar $50 \%$ dos custos operacionais da ETE. Além disso, o lodo pode ser prejudicial à saúde humana e os trabalhadores que atuam no seu manejo estão expostos a diversos riscos ocupacionais. Esta pesquisa tem como objetivo examinar a relação entre o manejo do lodo e os riscos ocupacionais associados, por meio de processos de gestão de riscos, baseados na ISO 31000, em duas ETEs de médio porte do interior paulista que utilizam tecnologias diferentes, lodos ativados convencionais e reatores anaeróbios UASB. Dentre os principais riscos ocupacionais avaliados, foram considerados críticos a exposição a microrganismos patogênicos dispersos no ar e no contato direto acidentale o risco de acionamentos acidentais de equipamentos durante a manutenção. Percebese que ainda há muita resistência, tanto dos trabalhadores como dos empregadores, em relação à saúde e segurança do trabalho. Muito se deve a fatores culturais e sociais, e, portanto, sempre haverá a necessidade da atualização dos instrumentos legais e intensificação da fiscalização. Além disso, é necessário promover, de forma frequente, a conscientização dos trabalhadores e, principalmente, dos empregadores, discutindo o papel dos gestores dos serviços de saneamento básico, em especial no tratamento de esgotos, no processo de desenvolvimento de cultura de segurança do trabalho nas empresas.

Palavras-chave: Manejo de lodo de Esgoto. Lodo de Esgoto. Gestão de Riscos Ocupacionais. Saúde e Segurança do Trabalho. ISO 31000.

\section{Abstract}

The wastewater treatment plants (WWTP) play a crucial role in maintaining the health of the population. However, they generate a considerable amount of sewage sludge. The costs related to the management of sewage sludge can represent $50 \%$ of the operational costs of the WWTP. In addition, WWTP Sludge can be harmful to human health, and workers who act in their management are exposed to various occupational risks. This research aims to study the relationship between the sewage sludge management and associated occupational risks, through a risk management proposal, based on ISO 31000, in two medium-sized WWTP in the interior of São Paulo, using different technologies, conventional activated

\footnotetext{
${ }^{1}$ UFSCar (Universidade Federal de São Carlos) - São Carlos - São Paulo - Brasil.

* Autor correspondente: alyssonrogerioagmail.com.
} 
sludge and UASB anaerobic reactors. Among the main occupational risks evaluated, exposure to pathogenic microorganisms dispersed in the air and in direct accidental contact, and the risk of accidental drives of equipment during maintenance were considered critical. It can be seen that there is still a lot of resistance, both from workers and from employers, regarding health and safety at work. Much is due to cultural and social factors, therefore there will always be a need to update legal instruments and intensify surveillance. In addition, it is necessary to promote, on a frequent basis, the awareness of workers and, especially, of employers, discussing the role of managers of basic sanitation services, especially in the treatment of sewage, in the process of development of safety culture of work in the companies.

Keywords: Sewage Sludge Management. Sewage Sludge. Occupational Risk Management. Health and Safety at work. ISO 31000.

\section{INTRODUÇÃO}

O aumento populacional, aliado ao grande consumo de água pela agricultura, altera as fontes disponíveis, em parte devido à disposição inadequada de resíduos e esgotos in natura. Nesse contexto, as estações de tratamento de esgoto (ETE) surgem com papéis cruciais para a preservação ambiental e a manutenção da saúde da população. Contudo, no Brasil há um déficit importante em relação ao tratamento do esgoto. De acordo com os dados do Sistema Nacional de Informações sobre Saneamento (SNIS, 2016), apenas $52 \%$ da população brasileira tem acesso à coleta de esgoto e, destes, apenas $45 \%$ recebem tratamento, o que representa mais de 150 milhões de brasileiros sem acesso ao tratamento de esgoto.

Ainda assim, as ETE geram um volume considerável de resíduos sólidos, sendo o lodo de esgoto (LETE) o principal. Pode representar de 1 a $3 \%$ do volume de esgoto tratado, sendo constituído de, aproximadamente, $98 \%$ de água e $2 \%$ de sólidos, dos quais de 70 a $80 \%$ são constituídos de matéria orgânica. Além das altas concentrações de matéria orgânica (DBO e DQO), apresenta ainda fósforo, nitrogênioe metais pesados (TAO et al., 2012).

Por se tratar de resíduo sólido, só deveria ser encaminhado para aterro sanitário quando todas as possibilidades de destinação se esgotarem, conforme prevê a Política Nacional de Resíduos Sólidos (BRASIL, 2010). Entretanto, o LETE geralmente é adensado e estabilizado, para reduzir o volume e a quantidade de matéria orgânica e os microrganismos patogênicos, passa por desaguamento para facilitar seu transporte e é enviado e disposto em aterro sanitário como um rejeito, sem que seja destinado adequadamente por meio de recuperação, reúso ou reciclagem, como preconiza a lei. O reaproveitamento energético e o reúso na agricultura são métodos amplamente empregados em outros países, porém no Brasil ainda são pouco utilizados.

O manejo do LETE é bastante complexo, e seu custo elevado inclui as etapas de remoção, tratamento, destinação e disposição final. Estima-se que aproximadamente $50 \%$ dos custos de operação de uma ETE estejam associados ao manejo do LETE. Sendo assim, o manejo adequado, além de reduzir os impactos ambientais, pode contribuir com a redução de custos operacionais da ETE (METCALF et al., 2013).

Sabendo que o LETE pode ser prejudicial ao meio ambiente e à saúde humana, podemos perceber que os trabalhadores que atuam diretamente em seu manejo estão expostos a riscos que podem comprometer sua saúde e segurança. As condições do ambiente de trabalho influenciam dire- 
tamente a saúde e o bem-estar dos trabalhadores (AKAMANGWA, 2016).

Dessa forma, a justificativa principal do presente trabalho se pauta na ausência de amparo legal e de respaldo técnico/científico sobre o tema. Existem poucos trabalhos relacionados à saúde e à segurança dos trabalhadores que atuam no manejo do LETE. Este trabalho tem como objetivo entender o manejo do lodo, identificando e avaliando os riscos ocupacionais presentes e suas consequências potenciais na saúde e na segurança dos trabalhadores.

\section{METODOLOGIA}

O trabalho foi elaborado a partir de levantamento bibliográfico sobre o manejo do lodo de esgoto, suas formas de remoção, transporte, destinação, tratamento e disposição final, além da revisão sobre saúde e segurança ocupacional e gestão de riscos. Foram realizadas visitas técnicas e levantamento de dados in loco em duas ETEs localizadas no estado de São Paulo com diferentes tecnologias de tratamento (lodos ativados e reatores anaeróbios). A partir dos dados e informações obtidos, foram aplicadas metodologias de gestão de riscos conforme recomendado pela NBR ISO 31000. Na identificação dos riscos foram utilizados brainstorming e análise preliminar de riscos, e na análise e avaliação dos riscos foram utilizados índices de risco e matriz de probabilidade e consequência.

\section{RESULTADOS E DISCUSSÃO}

Mesmo se tratando de ETEs diferentes, tanto na tecnologia empregada como no porte e nível de automação, é possível realizar uma comparação de parâmetros, conforme apresentado na Tabela 1.

Tabela 1 - Comparação de Parâmetros das ETEs Visitadas.

\begin{tabular}{|c|c|c|}
\hline & ETE 1 & ETE 2 \\
\hline Tecnologia Empregada & Lodos Ativados & 27 \\
\hline$N^{0}$ de Funcionários Próprios & 38 & 600 litros por segundo \\
\hline Vazão de Esgoto & 1500 litros por segundo & 45,0 funcionários por $\mathrm{m}^{3}$ de esgoto tratado \\
\hline Relação entre No de funcionários e vazão tratada & 25,3 funcionários por $\mathrm{m}^{3}$ de esgoto tratado & $85 \%$ \\
\hline Eficiência de Remoção de Matéria Orgânica & $96 \%$ & 2008 \\
\hline Início da Operação da ETE & 2003 & \\
\hline
\end{tabular}

Fonte: Autor, 2019.

Pode-se destacar que a ETE 2, mesmo tendo iniciado sua operação mais recentemente (2008), apresenta eficiência e capacidade de tratamento (vazão) menores do que a ETE 1, e a quantidade de funcionários necessários para tratar a mesma quantidade de esgoto (custo operacional humano) é maior. Além disso, a eficiência de remoção de matéria orgânica é maior na ETE 1, porém a geração de lodo, como veremos a seguir, também é maior.

\subsection{Manejo de Lodo na ETE 1 - Lodos Ativados}

A partir das visitas realizadas, foi possível caracterizar o manejo do lodo na ETE 1 - lodos ativados, representado na Fig. 1. 


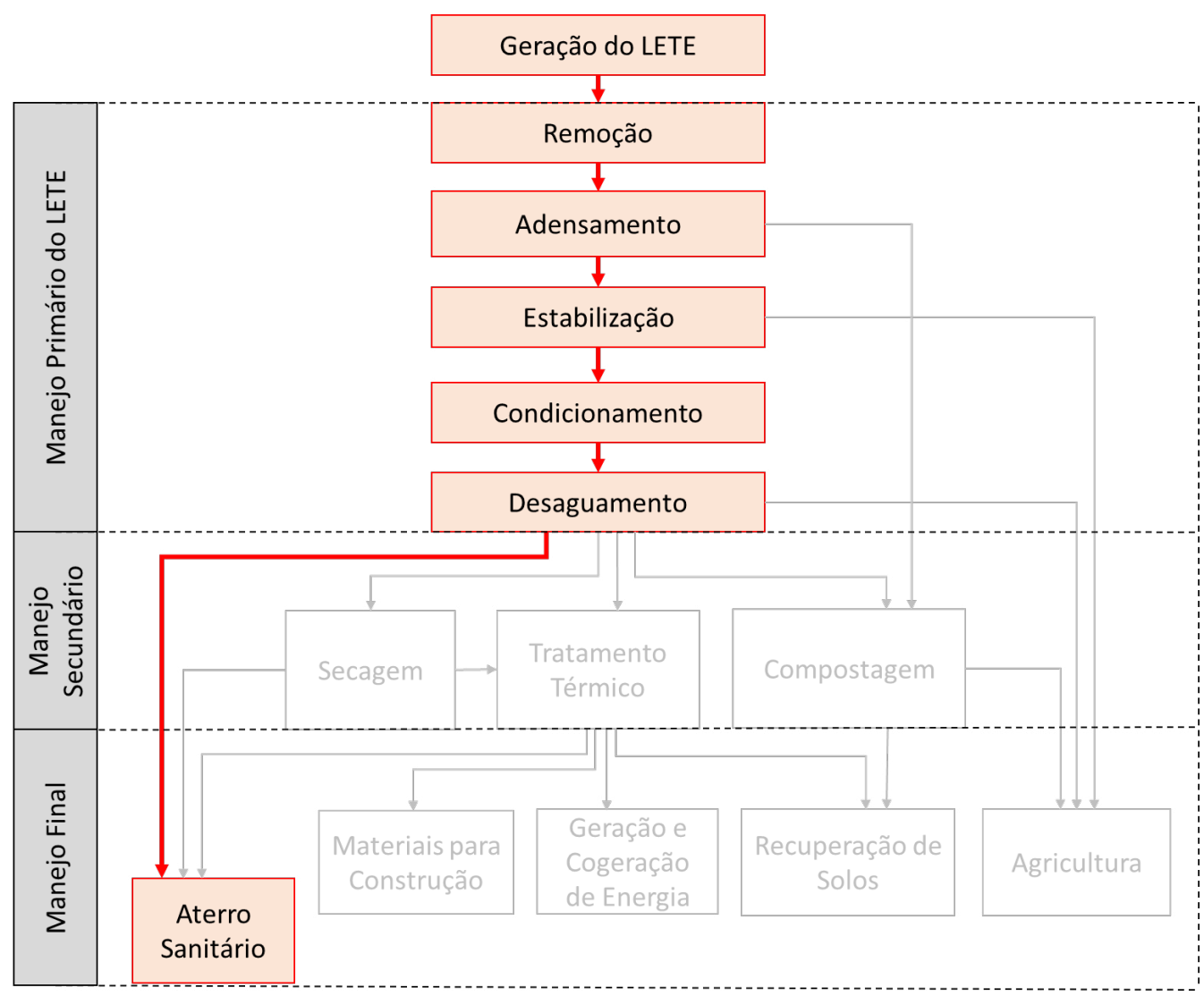

Figura 1 - Fluxograma do manejo do LETE na ETE 1 Fonte: Autor, 2019.

O manejo do LETE na ETE 1 pode ser considerado, exclusivamente, de nível primário, cujo objetivo se resume em reduzir o volume do LETE para baratear custos de transporte e disposição final em aterro sanitário. Posto que não é realizada nenhuma forma de manejo secundário, com o objetivo de preparar o LETE para a destinação (manejo final) por meio de recuperação, reúso ou reciclagem deste resíduo. 0 processo consiste na remoção do LETE dos decantadores primários e secundários, por meio de bombeamento em tubulações fechadas. Adiciona-se, então, polímero, e encaminha-se o LETE para tanque no qual ocorre o adensamento por gravidade e por flotação. O LETE adensado é então enviado, via bombeamento, para os digestores anaeróbios, para a estabilização do LETE. Posteriormente o
LETE é condicionado, com a adição de polímero catiônico, e desaguado pelo sistema mecânico de centrifugação. O LETE desaguado é então, bombeado e armazenado em silos verticais, até que seja carregado e transportado, por veículos (caminhões e carretas), para o aterro sanitário.

Mesmo em ETEs mecanizadas ou automatizadas, como no caso da ETE 1, onde o bombeamento do LETE ocorre em tubulações fechadas e, praticamente, todas os controles e acionamentos de válvulas são remotos, ainda assim, é possível identificar algumas interações importantes que expõem os trabalhadores a riscos. Podem-se destacar as seguintes interações principais:

- No local de coleta de amostras de LETE desaguado (Fig. 2); 
- No carregamento do LETE nos veículos de transporte (Fig. 3);

- Durante a manutenção de equipamentos e tubulações;

- No descarregamento e acondicionamento no aterro.

A coleta de amostras é realizada em local próximo aos silos de armazenamento do LETE e é realizada de forma manual. 0 operador aciona a válvula de abertura e o LETE desaguado verte em galeria aberta, e pode ser coletado, conforme Fig. 2. Após a coleta, é realizada a limpeza do local com mangueira de alta pressão. Esse processo é realizado com vestimentas não impermeáveis e luvas de proteção, porém verificou-se que os operadores não utilizam nenhuma proteção respiratória ou ocular.

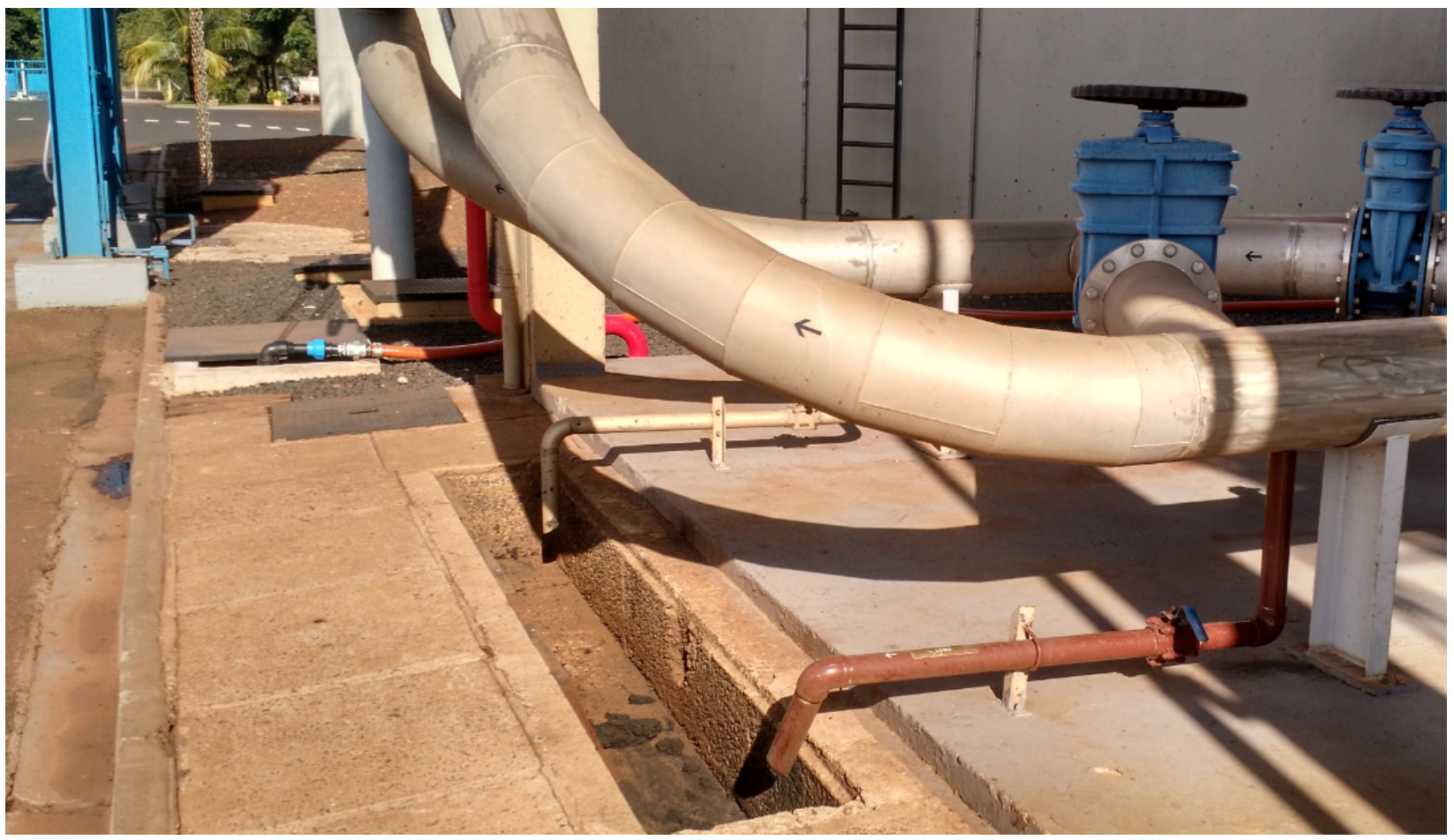

Figura 2 - Local de coleta de amostras do LETE desaguado. Fonte: Autor, 2018.

Próximo a esta área, ocorre também o carregamento do LETE. O veículo se posiciona sob os silos e estes são abertos manualmente (Fig. 3). Quando uma seção do compartimento de cargas se enche, o veículo se desloca, com o silo aberto. Nesse processo, é possível que haja a dispersão do resíduo no ar e no solo, expondo os operadores da ETE e os motoristas dos veículos ao LETE. 


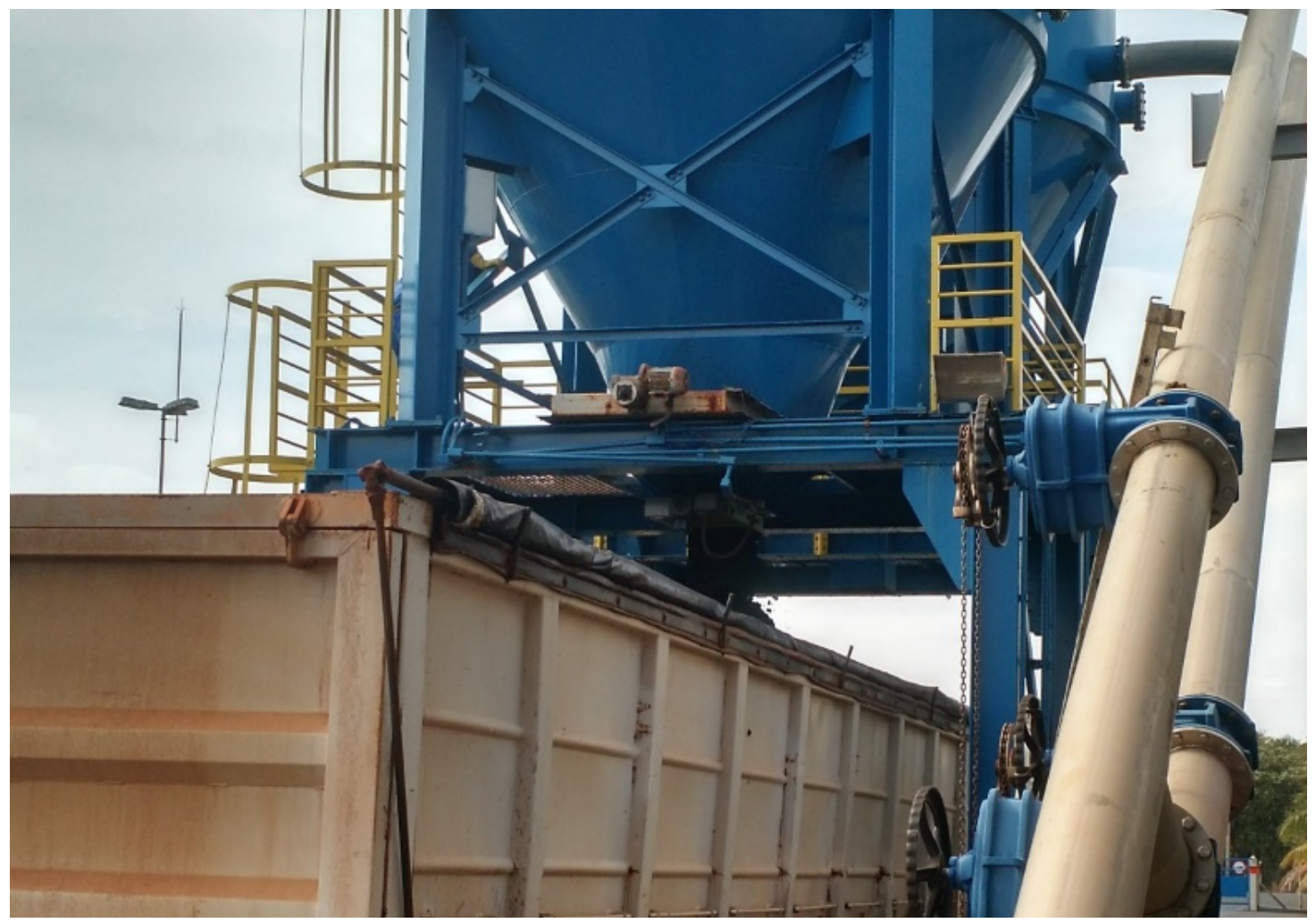

Figura 3 - Carregamento de LETE desidratado nos veículos. Fonte: Autor, 2018.

Existe ainda a necessidade periódica ou emergencial de reparos e manutenção nos equipamentos, centrifugas, tanques e tubulação, e pode haver exposição dos trabalhadores nesses processos. Além disso, no descarregamento e acondicionamento deste resíduo no aterro, pode haver exposição dos motoristas dos veículos e dos operadores do aterro sanitário. Outras interações são possíveis, como em atividades próximas às áreas dos reatores aerados, na adição de produtos nos tanques com lodo, entre outras.

A unidade apresenta nível de automação elevado. Todo o processo é controlado de forma automática, com exceção de poucas válvulas que são acionadas manualmente. Todo o lodo gerado nos decantadores é bombeado e transportado com o mínimo de contato com operadores; o armazenamento no silo e o carregamento dos caminhões de transporte ocorrem de forma mecanizada.
Na remoção do LETE primário e secundário dos decantadores, assim como na recirculação de LETE no reator aeróbio, é utilizado um sistema de bombeamento automatizado que não expõe os trabalhadores. No reator aeróbio e no adensamento pode haver a dispersão no ar de microrganismos patogênicos devido à aeração e floculação do LETE. No adensamento há a adição de polímero diretamente no tanque com o LETE, e na centrífuga pode haver o contato durante a operação e manutenção do equipamento. Entre a centrifugação e o armazenamento nos silos há o ponto de coleta de amostras do LETE desaguado, onde também pode ocorrer a exposição do LETE aos trabalhadores. O carregamento do LETE nos caminhões de transporte acontece em carrocerias abertas, que posteriormente serão cobertas, e também pode haver a dispersão no ar de partículas do LETE já desaguado, inclusive a 
queda de lodo no solo. E, por fim, o acondicionamento no aterro pode expor tanto o motorista do veículo como os operadores do aterro.

\subsection{Manejo de Lodo na ETE 2 - Reatores Anaeróbios UASB}

De forma semelhante, o manejo do LETE na ETE 2 com Reatores anaeróbios do tipo UASB também pode ser considerado como exclusivamente de nível primário, cujo objetivo se resume em reduzir o volume do LETE a fim de diminuir custos de transporte e disposição final em aterro. Com o diferencial que o LETE de origem anaeróbia, assim como o LETE de origem físico-químico, não necessita de estabilização como o LETE aeróbio (ETE 1). O fluxograma do manejo do lodo na ETE 2 é apresentado na Fig. 4.

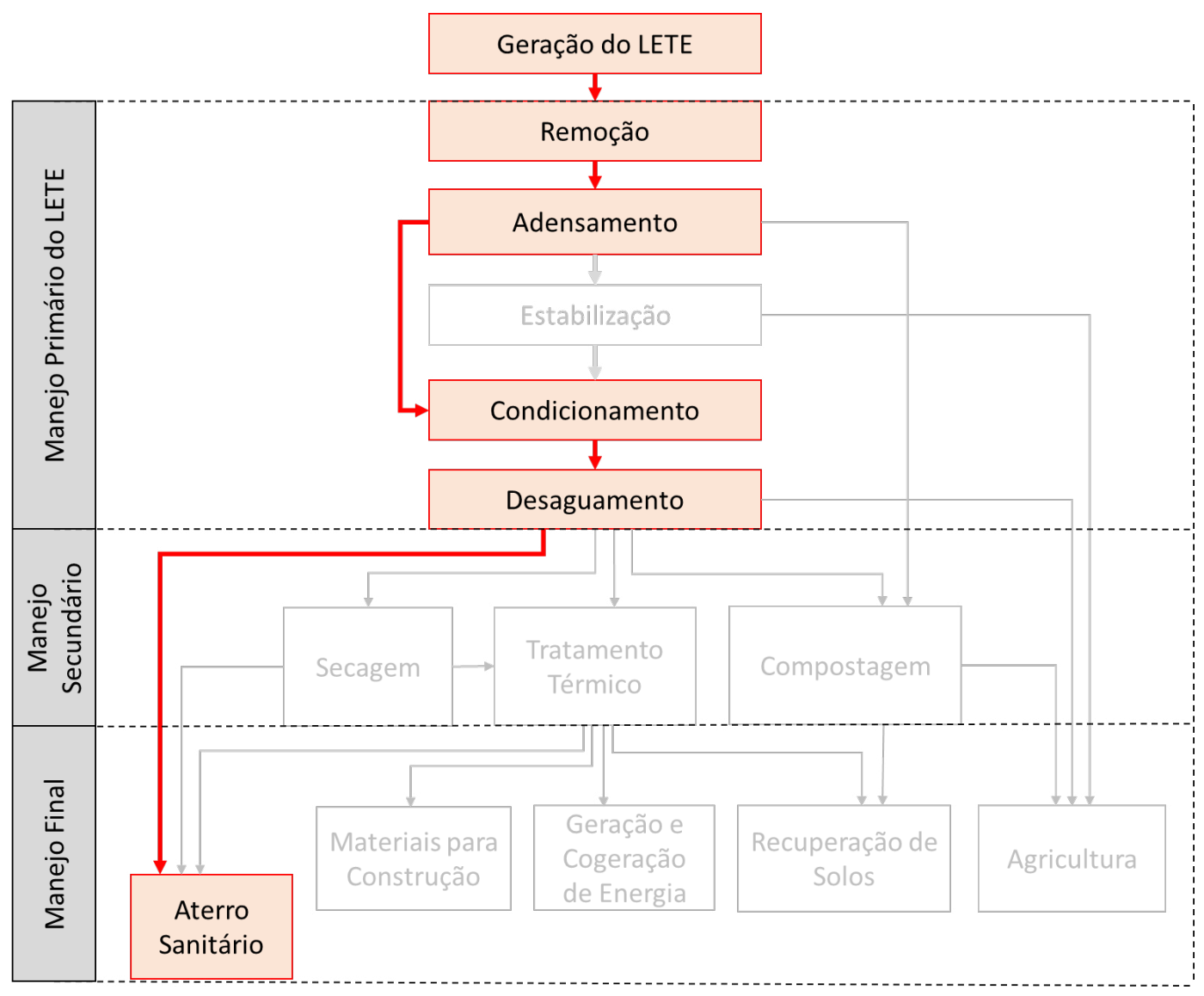

Figura 4 - Fluxograma do manejo do LETE na ETE 2.

Fonte: Autor, 2018.

O manejo consiste na remoção do LETE dos reatores UASB, que ocorre de forma manual, com a abertura de válvulas na lateral dos reatores. Além disso, há a remoção de LETE dos flotadores (coagulação, floculação e flotação) por meio de raspadores e canaletas (LETE da porção superior) e da drenagem do fundo (parcela de LETE que sedimenta). O LETE adensado segue para câmara de armazenamento e de mistura. É então, condicionado com a utilização de polímero catiônico (condicionamento) e desaguado por centrifugação. Segue para transportadores mecânicos 
(rosca sem fim) que carregam as caçambas de armazenamento que serão, por fim, enviadas para o aterro sanitário.

A ETE 2 apresenta nível de mecanização ou automação que pode ser considerado intermediário, se comparado com a ETE 1. Onde o transporte interno do LETE ocorre em galerias abertas e tubulações fechadas, os acionamentos de válvulas e controles são manuais, o raspador de lodo do flotador é mecanizado. Sendo assim, foi possível identificar as principais interações que expõem os trabalhadores ao LETE durante o manejo. Podemse destacar as seguintes interações principais:

- Na remoção do LETE dos reatores UASB (Fig. 5);

- Nas áreas próximas dos flotadores por ar dissolvido;
- No armazenamento e carregamento do LETE nos veículos (Fig. 6);

- Durante a manutenção de equipamentos e tubulações;

- No descarregamento e acondicionamento no aterro.

A remoção do LETE dos reatores ocorre por sistema localizado na lateral dos reatores anaeróbios. $\mathrm{O}$ operador aciona as válvulas de abertura de forma manual e o LETE verte em galeria aberta. Ocorre, então, a dispersão do resíduo no ar. Esse processo é realizado com vestimentas não impermeáveis, sem luvas de proteção, proteção respiratória ou ocular. 0 sistema de remoção é apresentado na Fig. 5.

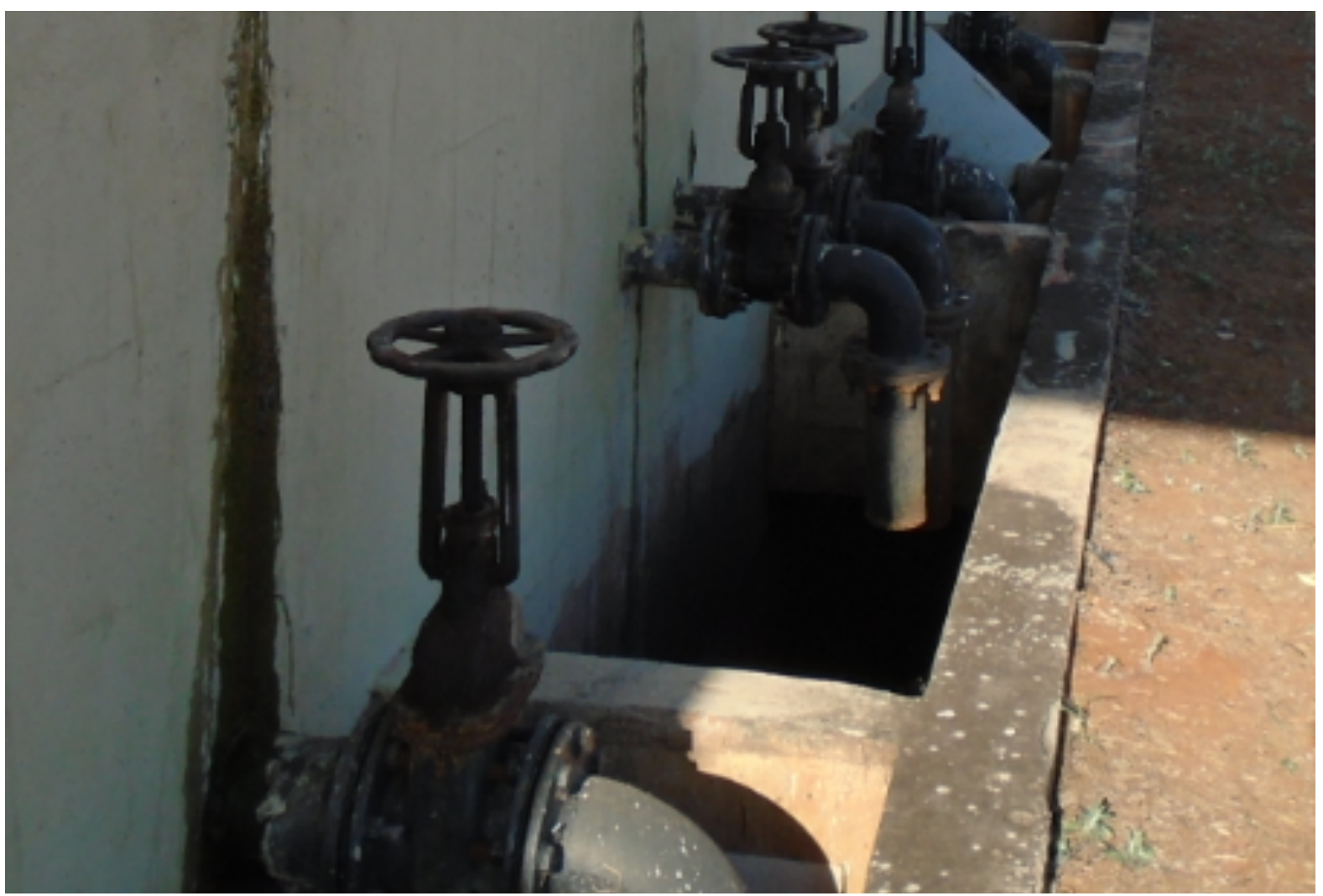

Figura 5 - Sistema de remoção do LETE dos reatores UASB. Fonte: Autor, 2018. 
A remoção do LETE dos flotadores por ar dissolvido ocorre de forma mecanizada (raspadores de superfície e dreno), porém nas áreas próximas é possível que haja dispersão do resíduo no ar, expondo os operadores ao LETE na forma de "sprays" ou bioaerossóis. O armazenamento e carregamento do LETE nos veículos ocorre por meio do transporte do LETE desaguado por sistema mecanizado do tipo rosca sem fim, que transporta o lodo em dutos abertos até as caçambas de armazenado (Fig. 6). Nesse processo é possível que haja a dispersão do resíduo no are no solo, expondo os operadores da ETE ao LETE.

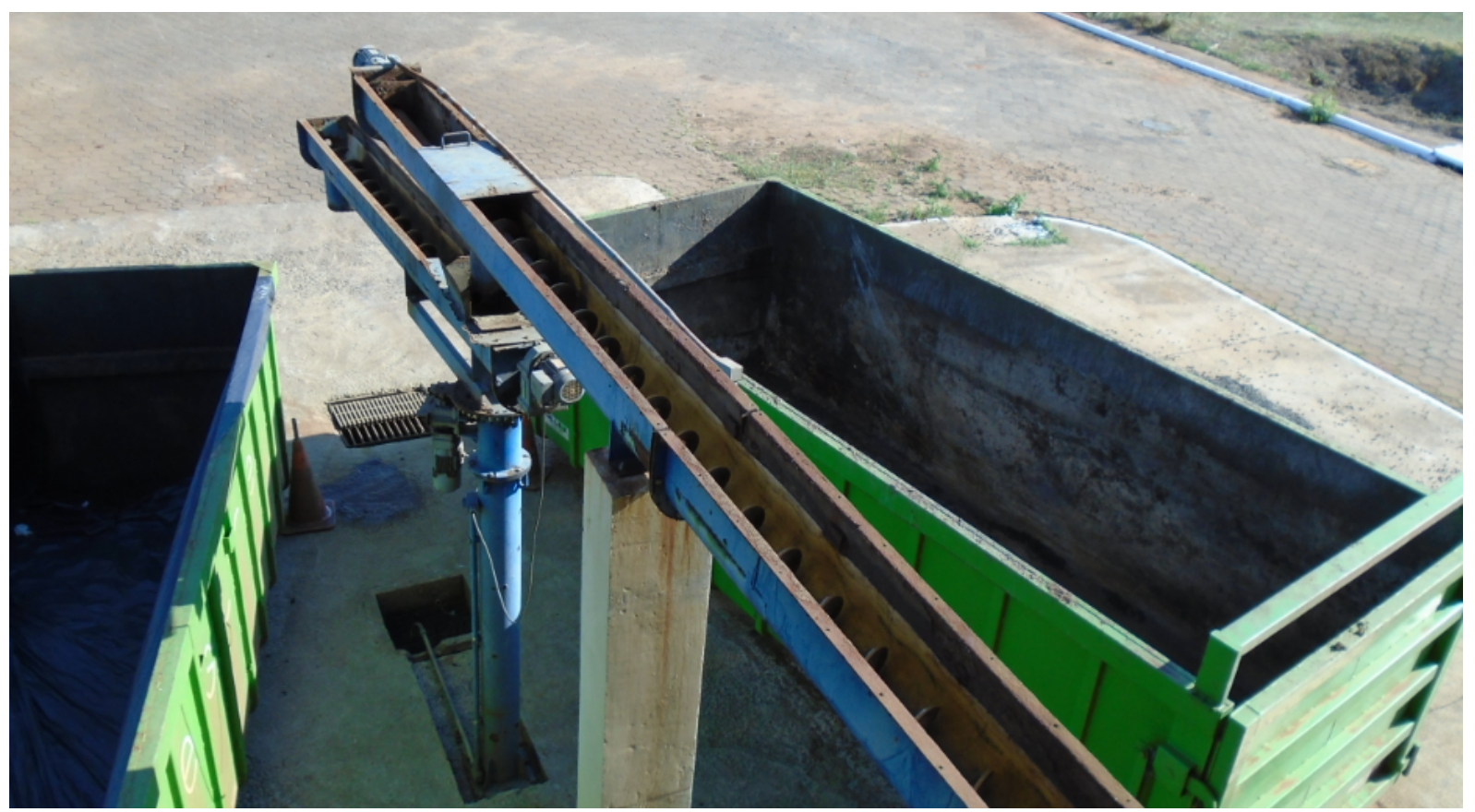

Figura 6 - Sistema de transporte e armazenamento do LETE. Fonte: Autor, 2017.

Há ainda a necessidade periódica ou emergencial de reparos, manutenção e limpeza nos equipamentos, centrífuga, reatores e tubulações, e pode haver a exposição dos trabalhadores. Além disso, no descarregamento e acondicionamento do LETE no aterro pode haver a exposição dos motoristas e dos operadores do aterro sanitário. $\mathrm{Na}$ remoção do LETE dos reatores anaeróbios é utilizado um sistema manual de abertura de registros que libera o LETE em galerias abertas a menos de 2 metros dos operados, o que os expõe ao LETE disperso no ar e nos registros; nesse processo não foi verificado o uso de EPIs adequados. No flotador e no adensamento também pode ocorrer a dispersão no ar do LETE nas áreas no entorno dos tanques devido a aeração e flotação. Na centrifugação há a adição de polímero diretamente no tanque. E na centrifugação pode haver o contato durante a operação e manutenção. $O$ sistema de carregamento do LETE nas caçambas é mecânico (rosca sem fim), onde também pode ocorrer a exposição dos trabalhadores. 0 carregamento do LETE nos caminhões de transporte acontece em carrocerias abertas, que posteriormente serão co- 
bertas, e também pode haver a dispersão no ar de partículas do LETE. Por fim, o acondicionamento no aterro pode expor tanto o motorista do veículo como os operadores do aterro.

\subsection{Gestão de Riscos Ocupacionais}

O processo de gestão de risco se inicia na definição dos parâmetros a serem levados em consideração e na identificação dos possíveis riscos que podem de alguma forma comprometer a atividade. Posteriormente são realizadas a análise e a avaliação desses riscos identificados e, final- mente, o tratamento e o monitoramento. Segundo a norma (NBR ISO 31000), a identificação de riscos é "o processo de encontrar, reconhecer e registrar os riscos." Nada mais é do que a determinação dos riscos que podem afetar a atividade; no caso deste trabalho, são os riscos que podem afetar a saúde e segurança dos trabalhadores que atuam diretamente no manejo do LETE. A finalidade deste processo é identificar situações que possam afetar a realização da atividade; em outras palavras, o processo junta a identificação de causa e origens do risco. $O$ processo de avaliação de riscos é apresentado na Fig. 7.

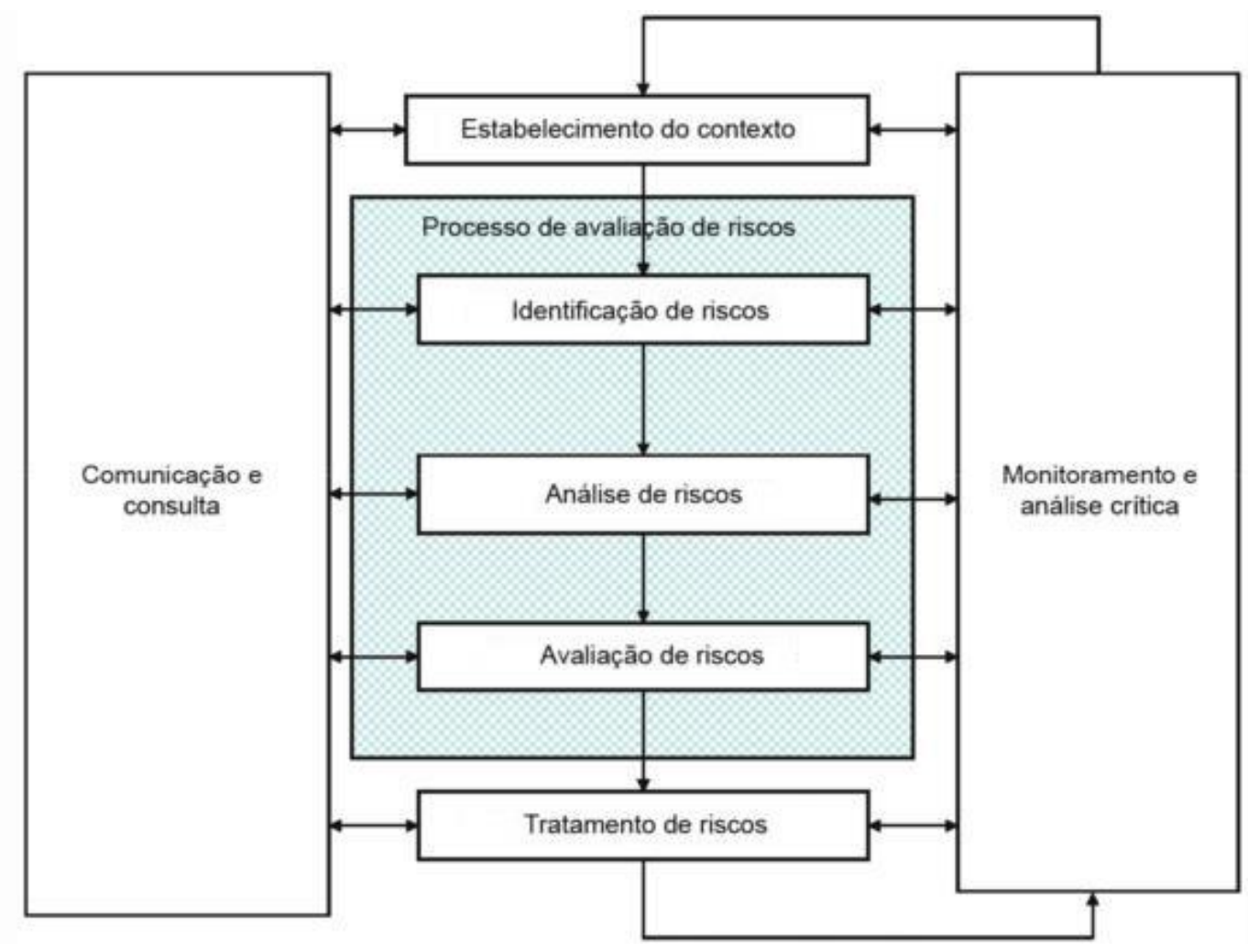

Figura 7 - Processo de Avaliação dos Riscos. Fonte: ABNT, 2012.

Por meio da visão sistêmica do manejo do LETE nas ETEs foi possível identificar os principais riscos ocupacionais presentes nas duas ETEs visitas. Na sequência, esses riscos identificados fo- ram analisados e avaliados de forma estruturada, para posterior tratamento e monitoramento das ações, concluindo assim, o ciclo de gestão com o objetivo de melhoria contínua. Mesmo os ris- 
cos do manejo do LETE variando, de acordo com a tecnologia empregada na ETE, etapas do manejo, nível de automação dos processos e gestão operacional; ainda assim, é possível destacar os principais riscos identificados no manejo do LETE das ETEs analisadas. As visitas e o Brainstorming forneceram um conjunto de potenciais riscos, resumidos na Tabela 2.

Tabela 2 - Principais riscos ocupacionais identificados.

\begin{tabular}{|c|c|}
\hline Tipo de risco & Descrição do risco \\
\hline Biológico & Exposição a Microrganismos Patogênicos \\
\hline Químico e Acidente & Formação de Atmosferas Perigosas (tóxicas, asfixiantes ou explosivas) \\
\hline Físico & Exposição a Ruído \\
\hline Físico & Exposição a Umidade \\
\hline Acidente & Acionamento Acidental (Máquinas e Equipamentos) \\
\hline Acidente & Quedas de Trabalhadores de Altura \\
\hline Acidente & Afogamento de Trabalhadores \\
\hline Acidente & Colisões de Veículos (Trânsito) \\
\hline Acidente & Animais Peçonhentos \\
\hline
\end{tabular}

Fonte: Autor, 2018.

Os riscos identificados incluem a exposição a agentes biológicos (microrganismos patogênicos), químicos (gases nocivos, como metano e sulfeto de hidrogênio), físicos (ruído e umidade), além de riscos de acidentes (explosões, quedas, acionamentos acidentais, afogamento, colisões e animais peçonhentos). Os riscos são provenientes das máquinas, ferramentas e equipamentos, procedimentos, insumos, produtos, subprodutos utilizados e da manipulação direta do LETE.

A partir das visitas e o do Brainstorming, que forneceram o conjunto inicial de informações, foi possível construir uma análise preliminar de riscos (APR). Esse tipo de análise consiste em método indutivo que permite analisar sistemas existentes e auxilia na priorização dos riscos. Pode ser utilizada quando há pouca informação disponível, como é o caso, pois informações detalhadas sobre número de acidentes, doenças ocupacionais, afastamentos, absenteísmo, custos com tratamento de saúde relacionadas ao manejo do LETE, são difíceis de obter.
Para a concepção da APR, os riscos identificados previamente são elencados em uma tabela sem ordem preestabelecida. Em seguida, os riscos foram classificados de acordo como a natureza de cada risco, em risco biológico, físico, químico, ou risco de acidente. A Tabela 3 apresenta a análise preliminar de riscos (APR) com os principais riscos identificados no manejo do LETE das ETEs visitadas e suas potenciais consequências.

A análise preliminar de riscos (APR) forneceu informações preliminares importantes, que foram analisadas e avaliadas de forma mais abrangente. A partir da APR foi possível estabelecer índices de risco e a matriz de probabilidade e consequência (Fig. 8). Por meio desse índice de risco e da matriz, é possível avaliar quais os riscos são mais críticos e relevantes, direcionando as medidas de controle de riscos de forma organizada e criteriosa. 
Tabela 3 - Análise preliminar de riscos (APR) no manejo do LETE.

\begin{tabular}{|c|c|c|c|c|}
\hline Atividades & $\begin{array}{l}\text { Risco } \\
\text { A/b/f/q }\end{array}$ & Perigo/ risco & Causas & Possíveis consequências \\
\hline \multirow{2}{*}{$\begin{array}{l}\text { Operação e Manutenção de Máquinas e } \\
\text { Equipamentos (Flotadores, centrifugas e } \\
\text { reatores); Remoção (UASB), Carregamento, } \\
\text { Armazenamento e Transporte do LETE }\end{array}$} & B & $\begin{array}{l}\text { Microrganismos } \\
\text { Patogênicos - } \\
\text { Dispersos no ar }\end{array}$ & $\begin{array}{l}\text { Dispersão no ar, na forma de } \\
\text { Bioaerossóis e sprays - } \\
\text { Vias Respiratórias }\end{array}$ & \multirow{2}{*}{$\begin{array}{l}\text { Doenças infecciosas e } \\
\text { parasitológicas, tuberculose, } \\
\text { brucelose, febre amarela, } \\
\text { hepatite e leptospirose }\end{array}$} \\
\hline & B & $\begin{array}{l}\text { Microrganismos } \\
\text { Patogênicos - } \\
\text { Contato direto }\end{array}$ & $\begin{array}{l}\text { Contato Acidental - Pele, olho, } \\
\text { boca e nariz }\end{array}$ & \\
\hline \multirow{2}{*}{$\begin{array}{l}\text { Operação e Manutenção de Máquinas e } \\
\text { Equipamento (decantadores, digestores } \\
\text { anaeróbios, flotadores, adensadores, } \\
\text { tanques); Remoção (UASB), Carregamento, } \\
\text { Armazenamento e Transporte do LETE; } \\
\text { Inspeções (canais e galerias) }\end{array}$} & Q & $\begin{array}{l}\text { Sulfeto de Hidrogênio } \\
\qquad\left(\mathrm{H}_{2} \mathrm{~S}\right)\end{array}$ & $\begin{array}{l}\text { Formação de atmosferas tóxicas } \\
\text { ou asfixiantes }\end{array}$ & $\begin{array}{l}\text { Irritações nos olhos, perda do } \\
\text { olfato, desconforto, desmaio e } \\
\text { morte (>500ppm) }\end{array}$ \\
\hline & Q & Metano $\left(\mathrm{CH}_{4}\right)$ & $\begin{array}{l}\text { Formação de atmosferas tóxicas } \\
\text { ou asfixiantes }\end{array}$ & Asfixia e morte \\
\hline $\begin{array}{c}\text { Operação e Manutenção das Bombas e } \\
\text { Centrífugas; Áreas próximas a Aeradores; Uso } \\
\text { de Lavadoras de Pressão para limpeza }\end{array}$ & $\mathrm{F}$ & Ruído & Máquinas e equipamentos & $\begin{array}{l}\text { Redução da concentração, } \\
\text { perda auditiva, hipertensão e } \\
\text { impotência sexual }\end{array}$ \\
\hline $\begin{array}{c}\text { Operação e Manutenção de Máquinas e } \\
\text { Equipamentos; Armazenamento e uso de } \\
\text { Biogás; ou Inspeções }\end{array}$ & A & Explosões & $\begin{array}{l}\text { Formação de } \\
\text { atmosferas explosivas }\end{array}$ & Queimaduras, traumas e morte \\
\hline \multirow{2}{*}{$\begin{array}{c}\text { Operação e Manutenção de Máquinas e } \\
\text { Equipamentos }\end{array}$} & A & Acionamento Acidental & $\begin{array}{l}\text { Máquinas e equipamentos } \\
\text { (manutenção) }\end{array}$ & $\begin{array}{l}\text { Contusões, escoriações, choques, } \\
\text { fraturas e morte }\end{array}$ \\
\hline & A & Queda de Altura & $\begin{array}{l}\text { Pisos e corrimões desprotegidos; } \\
\text { Enlonamento dos caminhões }\end{array}$ & $\begin{array}{l}\text { Contusões, escoriações, } \\
\text { fraturas e morte }\end{array}$ \\
\hline Transporte do LETE (ETE-Aterro) & A & Colisão de Veículo & Acidente de Trânsito & $\begin{array}{l}\text { Contusões, escoriações, } \\
\text { fraturas e morte }\end{array}$ \\
\hline $\begin{array}{c}\text { Operação e Manutenção de Máquinas e } \\
\text { Equipamentos; ou Transporte do LETE } \\
\text { (ETE-Aterro) }\end{array}$ & A & Animais Peçonhentos & Animais Peçonhentos & $\begin{array}{l}\text { Dor intensa, hemorragias, queda } \\
\text { da pressão arterial, choque } \\
\text { anafilático e morte }\end{array}$ \\
\hline
\end{tabular}

Fonte: Autor, 2019.

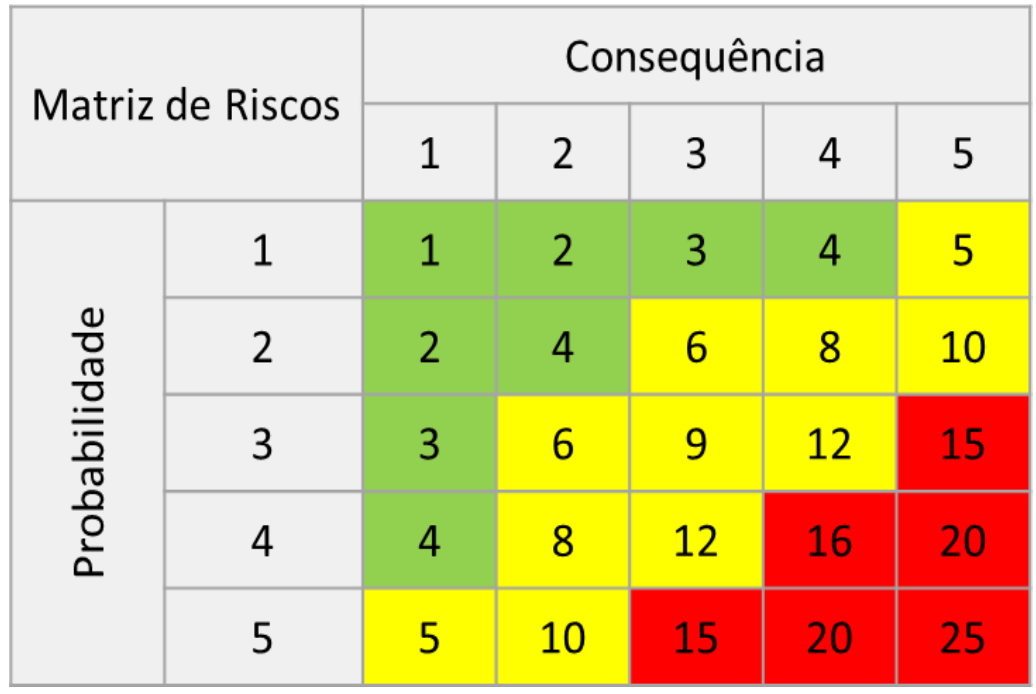

Figura 8 - Matriz de probabilidade x consequência adotada.

Fonte: Adaptado de ABNT, 2012.

Partindo dos referenciais teóricos de probabilidade e consequência estabelecidos e da matriz de risco proposta é possível estabelecer o índice ou nível de risco para cada um dos riscos identificados. O nível de risco representa a magnitude de cada risco, expressa em termos da combinação (multiplicação) das consequências e de suas probabilidades. Em relação aos critérios utilizados para graduar, seguiu-se o que foi proposto nos referenciais teóricos. Para probabilidades abaixo de 10\% (muito 
improvável), foi estabelecida a menor magnitude (peso 1), de 10-30\% (improvável) foi dado peso 2, e assim sucessivamente até o peso 5 (muito provável) para situações com probabilidade acima de $80 \%$. Para consequência, foi considerada a pior situação quando há várias consequências possíveis. Se há a possibilidade, ainda que mínima, de causa, a morte foi considerada o maior peso (5) e assim por diante.
Nas Tabelas 4 e 5, são apresentadas as análises e avaliações dos principais riscos identificados no manejo do LETE, respectivamente, para a ETE 1 (lodos ativados) e ETE 2 (reatores anaeróbios UASB). Na Tabela 6 podem-se observar de forma comparativa os resultados dos níveis de riscos estabelecidos de cada um dos riscos identificados em ambas das ETEs avaliadas.

Tabela 4 - Avaliação dos riscos no manejo do LETE na ETE 1 (Lodos Ativados).

\begin{tabular}{|c|c|c|c|c|c|c|}
\hline $\begin{array}{l}\text { Risco } \\
\text { A/b/f/q }\end{array}$ & Perigo/ Risco & Causas & $\begin{array}{l}\text { Possíveis } \\
\text { Consequências }\end{array}$ & $\begin{array}{l}\text { Probabilidade } \\
1 \text { - muito improvável } \\
2 \text { - improvável } \\
3 \text { - possível } \\
4 \text { - provável } \\
5 \text { - muito provável }\end{array}$ & $\begin{array}{l}\text { Consequência } \\
1 \text { - baixíssimo } \\
2 \text { - baixo } \\
3 \text { - moderado } \\
4 \text { - alto } \\
5 \text { - altíssimo }\end{array}$ & $\begin{array}{l}\text { Nível de risco } \\
\text { (probabilidade x } \\
\text { consequência) }\end{array}$ \\
\hline B & $\begin{array}{l}\text { Microrganismos } \\
\text { Patogênicos - } \\
\text { Dispersos no ar }\end{array}$ & $\begin{array}{c}\text { Dispersão no ar, na } \\
\text { forma de Bioaerossóis } \\
\text { e sprays - Vias } \\
\text { Respiratórias }\end{array}$ & \multirow{2}{*}{$\begin{array}{l}\text { Doenças infecciosas } \\
\text { e parasitológicas, } \\
\text { tuberculose, } \\
\text { brucelose, febre } \\
\text { amarela, hepatite e } \\
\text { leptospirose }\end{array}$} & 3 & 4 & 12 \\
\hline B & $\begin{array}{c}\text { Microrganismos } \\
\text { Patogênicos - Contato } \\
\text { direto }\end{array}$ & $\begin{array}{l}\text { Contato Acidental - } \\
\text { Pele, olho, boca e nariz }\end{array}$ & & 3 & 4 & 12 \\
\hline Q & $\begin{array}{l}\text { Sulfeto de Hidrogênio } \\
\qquad\left(\mathrm{H}_{2} \mathrm{~S}\right)\end{array}$ & $\begin{array}{l}\text { Formação de } \\
\text { atmosferas tóxicas ou } \\
\text { asfixiantes }\end{array}$ & $\begin{array}{l}\text { Irritações nos olhos, } \\
\text { perda do olfato, } \\
\text { desconforto, desmaio } \\
\text { e morte (>500ppm) }\end{array}$ & 2 & 5 & 10 \\
\hline Q & Metano $\left(\mathrm{CH}_{4}\right)$ & $\begin{array}{l}\text { Formação de } \\
\text { atmosferas tóxicas ou } \\
\text { asfixiantes }\end{array}$ & Asfixia e morte & 2 & 5 & 10 \\
\hline $\mathrm{F}$ & Ruído & $\begin{array}{l}\text { Máquinas e } \\
\text { equipamentos }\end{array}$ & $\begin{array}{c}\text { Redução da } \\
\text { concentração, perda } \\
\text { auditiva, hipertensão e } \\
\text { impotência sexual }\end{array}$ & 4 & 3 & 12 \\
\hline$A$ & Explosões & $\begin{array}{c}\text { Formação de } \\
\text { atmosferas explosivas }\end{array}$ & $\begin{array}{l}\text { Queimaduras, } \\
\text { traumas e morte }\end{array}$ & 2 & 5 & 10 \\
\hline$A$ & $\begin{array}{l}\text { Acionamento } \\
\text { Acidental }\end{array}$ & $\begin{array}{l}\text { Máquinas e } \\
\text { equipamentos } \\
\text { (manutenção) }\end{array}$ & $\begin{array}{l}\text { Contusões, } \\
\text { escoriações, choques, } \\
\text { fraturas e morte }\end{array}$ & 2 & 5 & 10 \\
\hline$A$ & Queda de Altura & $\begin{array}{l}\text { Pisos e corrimões } \\
\text { desprotegidos; } \\
\text { enlonamento dos } \\
\text { caminhões }\end{array}$ & $\begin{array}{l}\text { Contusões, } \\
\text { escoriações, } \\
\text { fraturas e morte }\end{array}$ & 2 & 5 & 10 \\
\hline$A$ & Colisão de Veículo & Acidente de Trânsito & $\begin{array}{l}\text { Contusõ } \\
\text { es, escoriações, } \\
\text { fraturas e morte }\end{array}$ & 2 & 5 & 10 \\
\hline$A$ & Animais Peçonhentos & Animais Peçonhentos & $\begin{array}{c}\text { Dor intensa, } \\
\text { hemorragias, queda } \\
\text { da pressão arterial, } \\
\text { choque anafilático } \\
\text { e morte }\end{array}$ & 2 & 5 & 10 \\
\hline
\end{tabular}

Fonte: Autor, 2019. 
Tabela 5 - Avaliação dos riscos no manejo do LETE na ETE 2 (Reatores UASB).

\begin{tabular}{|c|c|c|c|c|c|c|}
\hline $\begin{array}{l}\text { Risco } \\
\text { A/b/f/q }\end{array}$ & Perigo/ Risco & Causas & $\begin{array}{c}\text { Possíveis } \\
\text { Consequências }\end{array}$ & $\begin{array}{c}\text { Probabilidade } \\
\text { 1 - muito improvável } \\
2 \text { - improvável } \\
\text { 3-possível } \\
4 \text { - provável } \\
5 \text { - muito provável }\end{array}$ & $\begin{array}{l}\text { Consequência } \\
1 \text { - baixíssimo } \\
2 \text { - baixo } \\
3 \text { - moderado } \\
4 \text { - alto } \\
5 \text { - altíssimo }\end{array}$ & $\begin{array}{l}\text { Nível de risco } \\
\text { (probabilidade x } \\
\text { consequência) }\end{array}$ \\
\hline B & $\begin{array}{l}\text { Microrganismos } \\
\text { Patogênicos - } \\
\text { Dispersos no ar }\end{array}$ & $\begin{array}{c}\text { Dispersão no ar, na forma de } \\
\text { Bioaerossóis e sprays - Vias } \\
\text { Respiratórias }\end{array}$ & \multirow{2}{*}{$\begin{array}{c}\text { Doenças infecciosas } \\
\text { e parasitológicas, } \\
\text { tuberculose, brucelose, } \\
\text { febre amarela, hepatite } \\
\text { e leptospirose }\end{array}$} & 4 & 4 & 16 \\
\hline B & $\begin{array}{l}\text { Microrganismos } \\
\text { Patogênicos - } \\
\text { Contato direto }\end{array}$ & $\begin{array}{c}\text { Contato Acidental - Pele, } \\
\text { olho, boca e nariz }\end{array}$ & & 4 & 4 & 16 \\
\hline Q & $\begin{array}{c}\text { Sulfeto de } \\
\text { Hidrogênio }\left(\mathrm{H}_{2} \mathrm{~S}\right)\end{array}$ & $\begin{array}{l}\text { Formação de atmosferas } \\
\text { tóxicas ou asfixiantes }\end{array}$ & $\begin{array}{l}\text { Irritações nos olhos, } \\
\text { perda do olfato, } \\
\text { desconforto, desmaio e } \\
\text { morte (>500ppm) }\end{array}$ & 2 & 5 & 10 \\
\hline Q & Metano $\left(\mathrm{CH}_{4}\right)$ & $\begin{array}{l}\text { Formação de atmosferas } \\
\text { tóxicas ou asfixiantes }\end{array}$ & Asfixia e morte & 2 & 5 & 10 \\
\hline$A$ & Explosões & $\begin{array}{l}\text { Formação de atmosferas } \\
\text { explosivas }\end{array}$ & $\begin{array}{l}\text { Queimaduras, traumas } \\
\text { e morte }\end{array}$ & 2 & 5 & 10 \\
\hline A & $\begin{array}{l}\text { Acionamento } \\
\text { Acidental }\end{array}$ & $\begin{array}{c}\text { Máquinas e equipamentos } \\
\text { (manutenção) }\end{array}$ & $\begin{array}{c}\text { Contusões, escoriações, } \\
\text { choques, fraturas e } \\
\text { morte }\end{array}$ & 3 & 5 & 15 \\
\hline A & Queda de Altura & $\begin{array}{l}\text { Pisos e corrimões } \\
\text { desprotegidos; } \\
\text { enlonamento dos } \\
\text { caminhões }\end{array}$ & $\begin{array}{l}\text { Contusões, escoriações, } \\
\text { fraturas e morte }\end{array}$ & 2 & 5 & 10 \\
\hline A & $\begin{array}{l}\text { Colisão de } \\
\text { Veículo }\end{array}$ & Acidente de Trânsito & $\begin{array}{l}\text { Contusões, escoriações, } \\
\text { fraturas e morte }\end{array}$ & 2 & 5 & 10 \\
\hline$A$ & $\begin{array}{c}\text { Animais } \\
\text { Peçonhentos }\end{array}$ & Animais Peçonhentos & $\begin{array}{l}\text { Dor intensa, } \\
\text { hemorragias, queda da } \\
\text { pressão arterial, choque } \\
\text { anafilático e morte }\end{array}$ & 2 & 5 & 10 \\
\hline
\end{tabular}

Fonte: Autor, 2019.

Tabela 6 - Avaliação comparativa dos riscos no manejo do LETE das ETEs avaliadas.

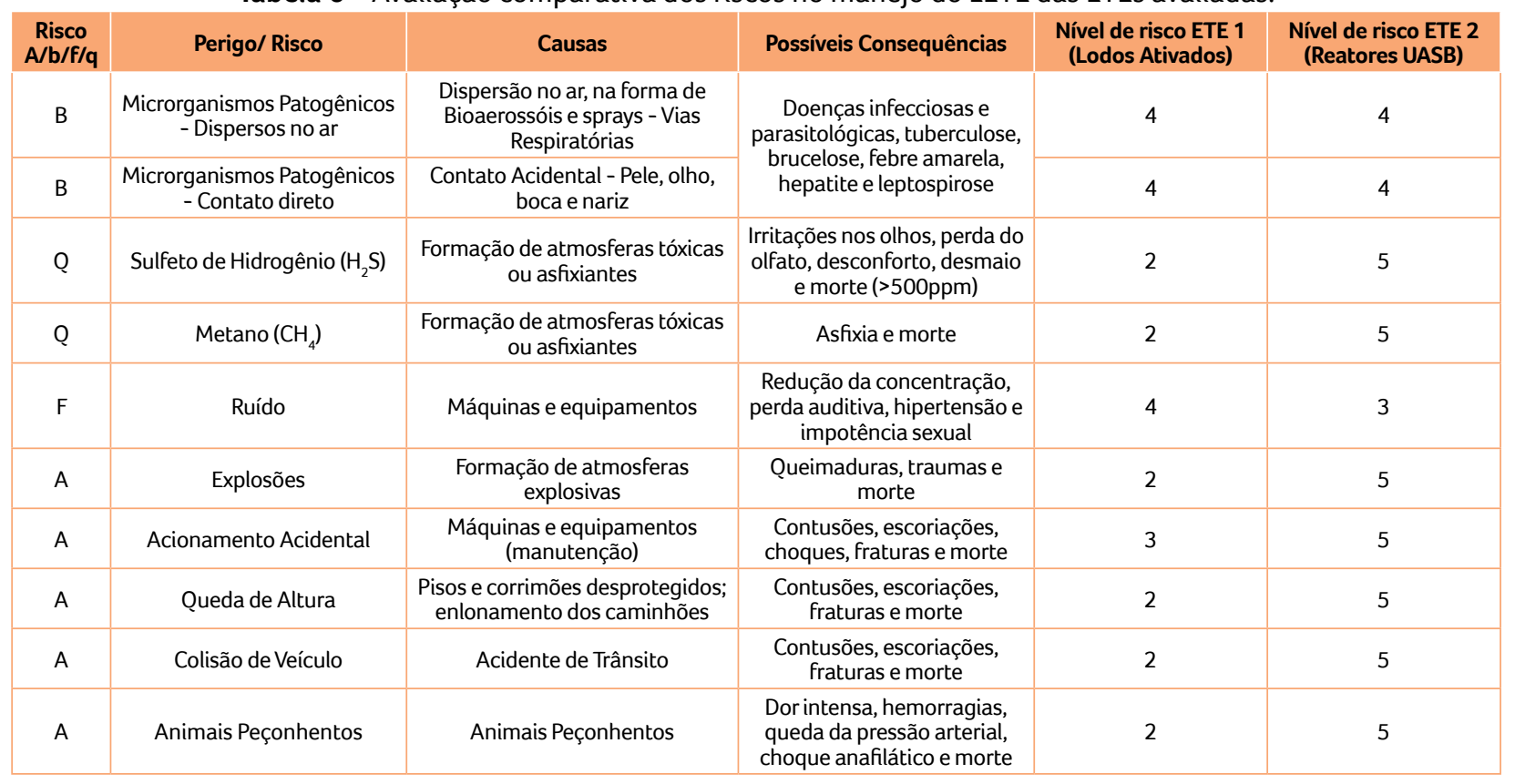

Fonte: Autor, 2019. 


\subsection{Riscos Críticos}

Não houve riscos considerados críticos na ETE 1. Nenhum dos riscos analisados e avaliados no manejo do LETE nesta ETE superou o índice de risco estabelecido na matriz de risco como crítico, valor numérico acima de 12 (vermelho na matriz) na tabela de análise e avaliação de riscos (Tabela 4). No manejo do LETE na ETE 2 o risco biológico, de exposição a microrganismos potencialmente perigosos, e o risco de acidente, de acionamento acidental de máquinas e equipamentos, foram considerados críticos e devem ser priorizados no direcionamento de ações de controle. É necessário ainda, a implementação imediata de medidas para que se continue com a atividade. Além disso, faz-se necessária uma avaliação mais específica, quantitativa e detalhada de cada um desses riscos em particular, tanto para validar a presente avaliação como para detalhar os requisitos para o controle dessas ações.

A exposição aos agentes biológicos dispersos no ar e/ou o contato direto do trabalhador na ETE 2 alcançou valores considerados altos (16) em escala de 1 a 25. Mesmo não tendo o potencial de levar à morte, as consequências dessa exposição podem provocar doenças infecciosas e parasitológicas graves. Além disso, a exposição pode ocorrer em diversas atividades, como na operação e manutenção dos flotadores, centrifugas e reatores anaeróbios; na remoção do LETE dos reatores; no carregamento das caçambas; na coleta de amostras; no transporte do LETE; e no armazenamento no aterro sanitário.

As principais rotas de entrada, no corpo humano, para os contaminantes de natureza biológica são as vias respiratórias (inalação) e o contato direto com a pele. Como visto anteriormente, existe, tanto na remoção do LETE dos reatores UASB como na flotação por ar dissolvido na ETE 2, a dispersão de partículas (bioaerossóis) que são transportadas pelo ar. Logo, existem algumas áreas, próximas a essas operações, que re- cebem essa carga de materiais suspensos potencialmente perigosos. Eles podem, conforme as condições atmosféricas locais, ser transportados por longas distâncias. A maior parte do material inalado nas vias respiratórias é eliminado dos pulmões e engolido. Como resultado, a exposição respiratória e gastrointestinal pode ocorrer a partir de agentes biológicos inalados. Os microrganismos patogênicos também podem entrar no corpo através de ferimentos ou lesões na pele, e alguns podem entrar através das superfícies e mucosas dos olhos, nariz e boca. Porém, a forma mais comum de contaminação é o contato com as mãos durante a alimentação, ingestão de bebidas, manuseio de adornos, fumar, ou limpeza do rosto com as mãos ou luvas contaminadas. As infecções comumente estudadas entre esse grupo de trabalhadores (ETE) incluem leptospirose, hepatite e infecções por Helicobacter pylori (TIWARI, 2008).

O risco de acidente por acionamento acidental de máquinas ou equipamentos em manutenção também foi considerado crítico devido ao potencial lesivo desse tipo de acidente somado à frequência de manutenção das máquinas ou equipamentos envolvidos no manejo do LETE. Devem-se seguir todos os requisitos de segurança estabelecidos pelas normas NR-10 e NR-12, que estabelecem, respectivamente, requisitos de segurança em serviços em eletricidade, e segurança no trabalho em máquinas e equipamentos (BRASIL, 1978).

\subsection{Riscos Parcialmente Mitigados}

Os riscos considerados parcialmente mitigados são aqueles que necessitam de medidas complementares para tratar ou controlar o risco, mas, diferentemente dos riscos críticos, essas medidas não precisam de implementação imediata para que se continue com a atividade. Apresentam níveis de risco maiores que 4 e inferiores ou iguais a 12 (valores em amarelo na matriz). 
No manejo da ETE 1, todos os riscos avaliados foram considerados parcialmente mitigados. O risco biológico, de exposição a microrganismos potencialmente perigosos; o risco químico, de formação de atmosferas tóxicas ou asfixiantes; o risco físico de ruído na operação de equipamentos; e os riscos de acidentes, como explosões, de acionamento acidental, quedas, colisões e animais peçonhentos; apresentaram níveis de risco entre 4 e 12 . É necessário adotar medidas complementares, não consideradas críticas ou prioritárias.

Em ambas as ETEs, o risco químico, de exposição ao sulfeto de hidrogênio $\left(\mathrm{H}_{2} \mathrm{~S}\right)$ e metano $\left(\mathrm{CH}_{4}\right)$, foi considerado parcialmente mitigado (valor de nível de risco 10). Mesmo em baixas concentrações, o sulfeto de hidrogênio $\left(\mathrm{H}_{2} \mathrm{~S}\right)$ tem ação irritante nos olhos e no trato respiratório. Em casos de intoxicação leve (de 10 a 500 ppm), pode haver dor de cabeça por várias horas, dor nas pernas e, em alguns casos, pode haver síncope e perda de consciência. Em concentrações maiores (maiores que 500 ppm), pode haver perda de consciência, síncope e morte. O metano é considerado asfixiante simples. Pode formar misturas explosivas quando em contato com oxidantes e halogênios. A inalação do metano pode levar à inconsciência e lesar o sistema nervoso central, podendo provocar asfixia e morte. A acumulação e exposição a esses gases pode ocorrer na operação e manutenção de máquinas e equipamento (decantadores, reatores anaeróbios, flotadores, adensadores, e demais tanques), remoção do LETE (reatores UASB), carregamento, armazenamento e transporte do LETE (interno ou aterro); ou inspeções (canais de transporte de LETE e galerias). Os trabalhadores também são expostos a produtos químicos utilizados no manejo do LETE, como os polímeros. Os produtos químicos podem ainda ser absorvidos pela pele no contato com o LETE.
A exposição ao ruído proveniente do processo pode causar desde a redução da concentração, zumbidos, ansiedade e nervosismo, até a impotência sexual, perda da audição e hipertensão. No manejo do LETE em ambas estações, pode haver a exposição durante a operação ou manutenção das bombas e centrífugas, ou nas atividades que ocorrem em áreas próximas a aeradores, sopradores e lavadoras de alta-pressão (limpeza de rotina). É necessário um controle ambiental para avaliar as áreas e atividades expostas a esse risco para propor medidas de tratamento efetivas. Além disso, é necessário controle ocupacional da saúde auditiva dos trabalhadores expostos.

Alguns riscos de acidentes figuram entre parcialmente mitigados devido a sua consequência potencial de levar à morte dos trabalhadores acometidos. Pode-se citar o risco de explosões, devido à formação de atmosferas explosivas durante a operação e manutenção de instalações do manejo do LETE, desde inspeções de rotina em canais e tubulações de lodo, centrífuga, bombas, pontos de visitas, tanques, até a operação e manutenção de equipamentos (centrífuga, adensadores) próximo à área de armazenamento e uso de biogás por meio de geradores (ETE 2). 0 risco de acidente por acionamento acidental de máquinas ou equipamentos em manutenção foi considerado crítico para o manejo do LETE na ETE 2 e parcialmente mitigado para a ETE1. O potencial lesivo desse tipo de acidente é o mesmo para ambos os casos, porém a frequência de manutenção das máquinas ou equipamentos envolvidos no manejo foi considerada maior na ETE 2. Os riscos de queda acidental de altura foram considerados parcialmente mitigados em ambas as ETEs. Tais situações podem ser causadas por superfícies escorregadias ou ausência de sinalização ou guarda-corpo, em tanques, decantadores, flotadores ou reatores, além de atividades em altura (escadas e andaimes) durante a operação e manutenção de instalações e equipamentos utilizados no manejo do LETE. Apresentam um alto potencial de gravida- 
de devido ao trauma da queda e possibilidade de afogamento ou contato com partes móveis dos equipamentos em operação.

Temos ainda o risco de acidentes com animais peçonhentos em áreas de armazenamento e acondicionamento do LETE como nos tanques, silos e caçambas. Os animais podem se aproximar desses locais atraídos pela possibilidade de alimentação e proteção. Os acidentes com esses animais podem levar ao óbito se não forem tratados de forma rápida e assertiva. Em ambos os casos (ETE 1 e ETE 2), esse risco foi considerado parcialmente mitigado.

Por fim, temos o risco de colisões entre veículos ou acidentes de trânsito durante o transporte do LETE até o aterro sanitário. Todos esses riscos podem causar desde consequências leves, como contusões e escoriações, até consequências graves, como fraturas, queimaduras e hemorragias, podendo chegar até ao óbito dos trabalhadores expostos.

Podem-se citar ainda os riscos ergonômicos, que podem estar presentes nas operações e atividades manuais de operação e manutenção. Estão relacionados com o esforço físico, levantamento de peso, postura inadequada, controle rígido de produtividade, situação de estresse, trabalhos em período noturno, jornada de trabalho prolongada, monotonia e repetitividade, imposição de rotina intensa. Podem provocar sérios danos à saúde do trabalhador pois geram alterações no organismo e no estado emocional, comprometendo sua produtividade, saúde e segurança. As alterações mais comuns são lesões por esforço repetitivo (LER), distúrbios osteomusculares (DORT), hipertensão arterial, alteração do sono, diabetes, depressão, ansiedade, doenças do aparelho digestivo (gastrite e úlcera) e problemas de coluna, entre outros. Para evitar que esses riscos comprometam a saúde do trabalhador, é necessária uma análise ergonômica do trabalho, que deve ser conduzida por um profissional habilita- do nessa área (ergonomista) para indicar os ajustes necessários na relação do trabalhador com o ambiente de trabalho, como a melhoria no processo de trabalho, melhores condições no local de trabalho, modernização de máquinas e equipamentos, melhoria no relacionamento entre as pessoas, alteração no ritmo de trabalho, ferramentas adequadas, postura adequada, entre outras, conforme requisitos da NR-17 (BRASIL, 1978). Portanto, neste trabalho apenas citaremos o risco ergonômico; esse risco não será considerado na proposta de gestão de riscos.

\subsection{Riscos Mitigados}

São os riscos cuja intensidade é reduzida (níveis de risco abaixo ou iguais a 4 , em verde), pois tanto a probabilidade como a consequência são baixos, e, portanto, não requerem quaisquer medidas adicionais. Dos principais riscos analisados e avaliados no manejo do LETE das duas ETEs, nenhum se enquadrou como mitigado, pois nos riscos identificados não foram considerados riscos muito improváveis e com consequências consideradas leves.

\section{CONCLUSÕES}

A quantidade de LETE tende a aumentar nos próximos anos devido ao crescimento populacional e à instalação de novas ETE para atender o déficit de atendimento desse serviço essencial. A Política Nacional de Resíduos Sólidos estimula a não geração, redução, reutilização, reciclagem, tratamento e destinação final ambientalmente segura dos resíduos sólidos e com isso gera uma crescente demanda para a destinação adequada do LETE. No que diz respeito à destinação LETE, podemos perceber que a disposição final em aterros não está de acordo com os preceitos legais, mesmo sendo o destino principal desse resíduo no país. 
A partir dos estudos desenvolvidos, percebe-se que as condições de saúde e segurança do trabalho, de forma geral, deixam a desejar nas ETEs analisadas, em especial no manejo do LETE. As ferramentas de gestão de risco ocupacional são pouco utilizadas pelas empresas, em especial no Brasil. Mesmo em unidades modernas e bem planejadas, com o mínimo de contato dos resíduos com os trabalhadores, ainda existem riscos não gerenciados na manutenção de equipamentos, limpeza das instalações e transporte do LETE. Muitos dos problemas observados poderiam ser minimizados já na fase de projeto, outros na fase de elaboração dos procedimentos de operação. As empresas, por obrigação legal, precisam proporcionar aos trabalhadores ambiente laboral com as condições adequadas para o desempenho de suas funções e atividades, garantindo assim a saúde e integridade física, mental e social, eliminando, reduzindo ou controlando todo e qualquer risco presente e fornecendo soluções e condições adequadas de segurança, saúde, higiene, por meio de tecnologia e informação.

Em ambas as ETE visitadas não há manejo secundário, cujo objetivo é preparar o LETE para destinação por meio de recuperação, reúso ou reciclagem. A forma de manejo final selecionada é, exclusivamente, o transporte e a disposição final em aterro sanitário, o que contraria a Política Nacional de Resíduos Sólidos (Lei 12305/2010), que proíbe a disposição de resíduos em aterros sanitários, visto que ainda podem ser reaproveitados. Apenas os rejeitos (resíduos cuja possibilidade de tratamento e recuperação foi esgotada) podem ser destinados a aterros. Mesmo assim, o LETE, que é classificado como resíduo sólido, ainda é disposto em aterros sanitários.

O manejo realizado na ETE 1 apresenta poucos momentos de exposição direta dos trabalhadores ao LETE. Quase todo o processo é automatizado e/ou mecanizado, e ocorre em estrutura fechadas (tubulação, bombas e tanques). Exceto nos procedimentos de carregamento e descarregamento do LETE desaguado nos veículos de transporte, inspeções de rotina, coleta de amostras, manutenções preventivas e corretivas, operação da centrífuga e manipulação de produtos químicos (polímeros) nos tanques de preparação.

No manejo na ETE 2 existem mais ocasiões de exposição direta dos trabalhadores com o LETE. Parte do processo é automatizado e/ou mecanizado, porém há outros manuais, como a abertura de válvulas e registros. Algumas etapas ocorrem em estruturas fechadas (tubulação, bombas e tanques) e outras em estruturas abertas (flotador, canais de transporte do LETE, transporte e carregamento das caçambas). O manejo expõe os trabalhadores, em especial, nos procedimentos de remoção do LETE dos reatores anaeróbios, carregamento das caçambas, transporte do LETE desaguado nos caminhões/carretas, inspeções, coleta de amostras, manutenções preventivas e corretivas, operação da centrifuga, manipulação de produtos químicos (polímeros).

De forma geral, processos com menores níveis de automatização tentem a apresentar mais atividades manuais, que intensificam a exposição a alguns riscos. Nos casos estudados, as ETEs apresentam níveis de automatização diferentes, principalmente na remoção e carregamento do LETE. Ainda considerando os níveis de automatização, alguns riscos podem ser minimizados em sua origem. Como exemplo disso temos a remoção e o carregamento por meio de bombeamento em tubulações fechadas, que minimizam o contato do LETE com os trabalhadores. Além disso, a forma de armazenamento e carregamento do LETE desaguado pode ou não minimizar a exposição dos trabalhadores, como pudemos observar nos silos verticais fechados na ETE 1 e nos transportadores e caçambas abertas na ETE 2.

Por fim, ainda há muita resistência, tanto dos trabalhadores como dos empregadores, em relação 
a saúde e segurança do trabalho. Muito se deve a fatores culturais e sociais, e, portanto, sempre haverá a necessidade da atualização dos instrumentos legais e intensificação da fiscalização. Além disso, é necessário promover, de forma frequente e com alcance, a conscientização dos trabalhadores e empregadores, com o objetivo de desenvolver uma cultura de segurança nas empresas nacionais, seguindo alguns modelos estabelecidos em países considerados desenvolvidos, onde esse tipo de cultura se faz mais presente.

\section{CONTRIBUIÇÃO DOS AUTORES}

Todos os autores contribuíram de forma igualitária.

\section{REFERÊNCIAS}

ACHON, C.L., CORDEIRO, J.S. Gestão de resíduos dos serviços de saneamento (água e esgoto), a Lei 12.305/2010 e os desafios no Brasil. In: XXXV Congresso Interamericano de Engenharia Sanitária e Ambiental (AIDIS), Anais. Cartagena - Colombia. Anais... ID 1955, 7 p, 2016.

AKAMANGWA, N. Working for the environment and against safety: How compliance affects health and safety on board ships. Safety Science, v. 87, p 131-143, 2016. https://doi.org/10.1016/j. ssci.2016.03.027
ABNT - ASSOCIAÇÃO BRASILEIRA DE NORMAS TÉCNICAS. NBR ISO 31000:2009 - Gestão de Riscos - Princípios e diretrizes. Rio de Janeiro, RJ. ABNT, 2009. 24 p.

ABNT - ASSOCIAÇÃO BRASILEIRA DE NORMAS TÉCNICAS. NBR ISO/IEC 31010:2012 - Gestão de Riscos - Técnicas para o processo de avaliação de riscos. Rio de Janeiro, RJ. ABNT. 96 p, 2012.

BRASIL. Ministério do Trabalho e Emprego. Legislação Federal Brasileira. Brasília, DF. Portaria MTE 3.214 de 08 de junho de 1978. Aprova as Normas Regulamentadoras - NR - do Capítulo V, Título II, da Consolidação das Leis do Trabalho, relativas à Segurança e Medicina do Trabalho. Disponível em: <http://www4. planalto.gov.br/legislacao>. Acesso em: 31 mai. 2019.

BRASIL. Lei n. 12.305, de 2 de agosto de 2010. Institui a Política Nacional de Resíduos Sólidos e dá outras providências, Brasília, DF, 2010.

METCALF \& EDDY, TCHOBANOGLOUS G., STENSEL H.D., TSUCHIHASHI R., BURTON F. Wastewater Engineering: Treatment and Resource Recovery. 5 ed., McGraw-Hill Education, New York, 2013. ISBN: 9780073401188

SNIS - SISTEMA NACIONAL DE INFORMAÇÕES SOBRE SANEAMENTO. Ministério das Cidades. Secretaria Nacional de Saneamento Ambiental. Diagnóstico dos serviços de água e esgotos. Brasília, DF, 2016.

TAO, J., WU, S., SUN, L., TAN, X., YU, S., ZHANG, Z. Composition of Waste Sludge from Municipal Wastewater Treatment Plant. Procedia Environ. Sci., 12: 964-971, 2012. https://doi.org/10.1016/j. proenv.2012.01.372

TIWARI, R.R. Occupational health hazards in sewage and sanitary workers. Indian J Occup Environ Med. v.12(3), 2008, p.112-115. https://doi.org/10.4103/0019-5278.44691 